\title{
静電浮遊液滴の回転分裂挙動を用いた 非接触粘性測定法の開発 \\ Development of non-contact technology for measuring viscosity using breakup of rotating drop
}

\author{
前川知之* 松本聡** 阿部豊*** 金子暁子***
}

\section{Tomoyuki MAEKAWA, Satoshi MATSUMOTO, Yutaka ABE, and Akiko KANEKO}

The electrostatic levitation is utilized as one of the containerless processing techniques. Some recent investigations focus on thermal property measurement of high temperature molten metals with an oscillating droplet method. For example, viscosity has been estimated from the damping constant. However, this method is limited to the low viscosity fluid. Thus, the purpose of the present study is to develop method of wide viscosity measurement on a levitated liquid droplet. In the present study, the droplets with kinds of viscosity were levitated by the electrostatic force. Droplet deformation was induced by applying rotation. The followings are obtained connection rotational breakup and viscosity. The observed dynamics indicated that it is possible to measure physical property of levitated droplet.

[Keywords: levitated droplet, rotation, breakup, thermo physical property measurement]

\section{1. はじめに}

通常，溶融金属の熱物性測定の際，試料を保持するた めに, 耐火多孔質るつぼなどの容器が必要である。しか し溶融金属の温度が約 $2000^{\circ} \mathrm{C}$ を超えると, 容器が耐えら れなくなるため, 容器接触型の熱物性測定法は適用でき ない. 静電力で物体を浮かせる静電浮遊法を用いると, 容器を必要とせずに物体をある空間に保持でき, 試料に 対して擾乱が少ないことから, 未だ実測值のない超高温 融体の熱物性測定に用いられている[1-2]. 既存の物性測 定法には, 浮遊液滴に微小振動を印加し, この振動の減 衰時間から粘性係数を, 液滴の共振周波数から表面張力

\section{係数を算出する液滴振動法がある.}

* 筑波大学大学院システム情報工学研究科, $\overline{\mathbf{T}} 305-8573$

つくば市天王台 1-1-1. Graduate school of systems and information Engineering, University of Tsukuba, 1-1-1 Tennodai, Ibaraki 305-8573. FAX: 029-853-5487

E-mail: tmaekawa@edu.esys.tsukuba.ac.jp

** 宇宙航空研究開発機構, $\bar{\top} 305-8505$ つくば市千現 2-1-1. Institute of Space and Astronautical Science, Japan Aerospace Exploration Agency, 2-1-1 Sengen, Ibaraki 305-8505.

FAX: 029-868-3956 E-mail: matsumoto.satoshi@jaxa.jp

*** 筑波大学大学院システム情報工学研究科, $\bar{\top} 305-8573$ つ ば市天王台 1-1-1. Institute of Engineering Mechanics and Systems, University of Tsukuba, 1-1-1 Tennodai, Ibaraki 305-8573.

FAX: 029-853-5266 E-mail: abe@kz.tsukuba.ac.jp

*** 筑波大学大学院システム情報工学研究科, テ305-8573 つく ば市天王台 1-1-1. Institute of Engineering Mechanics and Systems, University of Tsukuba, 1-1-1 Tennodai, Ibaraki 305-8573. FAX: 029-853-5763 E-mail: kaneko@kz.tsukuba.ac.jp
しかし高粘性流体の場合, 変形振動を誘起できないため, 既存の非接触物性測定の適用範囲は粘性係数 $\eta=10^{-1} \mathrm{~Pa} \cdot \mathrm{s}$ 以下と限定されている. 一方, 非常に粘性の高い流体の 粘性計測法として, Ohsaka らにより形状緩和法(Shape relaxation method)が提案されている[3]. これは, 回転によ り変形した浮遊液滴の回転を止め, 液滴が球状に戻るま での時間から粘性係数を求める手法であり, 適用範囲は $\eta=10^{2} \mathrm{~Pa} \cdot \mathrm{s}$ 以上となっている[3]. よって, $\mathrm{BaTiO}_{3}$ などの 溶融酸化物では粘性係数が $10^{-1} \mathrm{~Pa} \cdot \mathrm{s}<\eta<10^{2} \mathrm{~Pa} \cdot \mathrm{s}$ の範囲 にあるものが多く，それら高温融体の粘性係数測定は困 難である．そのため，本研究では新たな粘性係数測定方 法の確立を目的とし, 静電浮遊液滴の回転挙動を観測し た. 回転数と液滴形状の関係, 液滴形状の時間変化を調 べ，新たな物性測定の可能性を検討した.

\section{2. 実験装置および実験条件}

\section{1 静電浮遊装置の原理}

本実験では，浮遊法の中でも静電気力を用いて物体を 浮遊させる静電浮遊法を用いる. 静電浮遊法の原理を Fig. 1 に示す. まず液滴の表面を正に帯電させ, 自重に打ち勝 つほどのクーロン力を鉛直上向きに発生させ，液滴を浮 かせる．同時にポジションディテクターにより浮遊液滴 の位置を検出し，自重とクーロン力が釣り合うように上 電極の電圧を調整する。この位置検出と電圧調整を高速 
で制御することで液滴をある位置に保持することが可能 である.

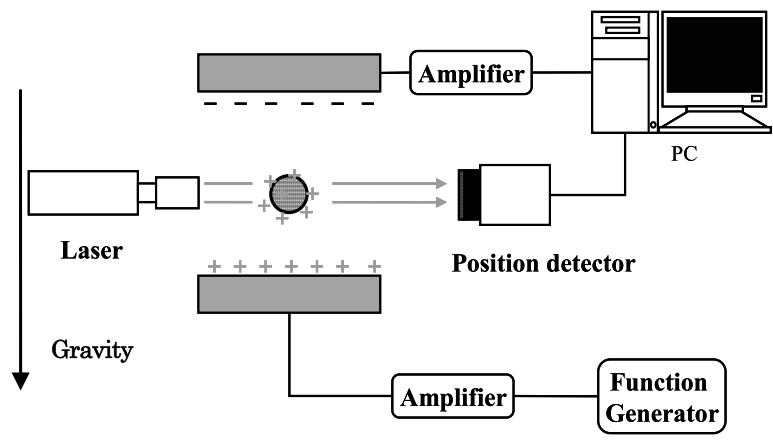

Fig. 1 Conceptual diagram of the electrostatic levitation

\section{2 実験装置}

本実験で用いた静電浮遊装置の概略図を Fig. 2 に示す. 図中の装置中央にアクリル製チャンバー(f)を配置し，そ の内部には上下に対となる電極(h)(i)を設置する．下電極 に取り付けられたシリンジ(j)から試料流体を注入し, 下電 極に正電圧を印加することで，液滴の表面を帯電させる． $\mathrm{He}-\mathrm{Ne}$ レーザ(a)とフォトディテクター(b)で液滴の位置情 報を常時検出する．液滴の自重とクーロン力が釣り合う ように, PID 制御により上電極の負電圧を高速で調整する ことで，安定した浮遊を行う。またチャンバー側面にラ インセンサー(c)を設置し, 液滴の初期直径および液滴の 振動振幅の時系列データを取得する.さらにチャンバー 側面には，それぞれの中心軸が直交するように 2 つの音

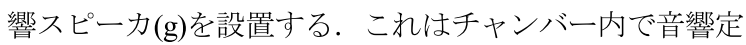
在波を発生させ，液滴に回転トルクを付与し，鉛直軸周 りの回転を誘起寸る[4]. スピーカーへの入力電圧を調整 することで液滴の回転数を制御する. 回転液滴は, 高速 度ビデオカメラ(d)(1)で水平方向および鉛直方向から同時 に撮影される，上電極には，導電性ガラスを埋め込み， 上部可視化が可能となっている. 液滴にはあらかじめト レーサ粒子(ナイロン粒子，直径 9〜13 $\mu \mathrm{m}$ )を混ぜ，撮影 動画から粒子を追跡することで回転数を計測する．また その動画から回転液滴の形状変化を計測する.ナイロン 製トレーサは試料流体と比べて誘電率が低いため, 電場 による外力を受けづらく, 液滴の流動に追従すると考え られる。

\section{3 試料流体および実験条件}

本実験では，低粘性流体としてプロピレンカーボネー 卜を，高粘性流体としてグリセリンとグルコースの混合
液を用いる．この混合溶液が均一に混ざり合うまでを擋 找を行った．試料流体の物性值を Table 1 に示す．実験は 全て常温常圧下で行い, 液滴の初期直径は $2.0 \mathrm{~mm}$ 前後と する. Table 中の表面張力係数は(株) 協和界面科学社製の 表面張力計によりプレート法で計測された実測值であり， 動粘度は毛細管粘度計である HANSEN 社製の高精度粘度 計 LAUDA Viscoboy2 により計測された実測值である.

Table 1 Physical property of test fluid

\begin{tabular}{l|c|c|c|c} 
& $\begin{array}{c}\text { Kinematic } \\
\text { viscosity } \\
v \mathrm{~mm}^{2} / \mathrm{s}\end{array}$ & $\begin{array}{c}\text { Specific } \\
\text { gravity }\end{array}$ & $\begin{array}{c}\text { Surface } \\
\text { tension } \\
\sigma \mathrm{mN} / \mathrm{m}\end{array}$ & $\begin{array}{c}\text { Viscosity } \\
\eta \mathrm{Pa} \cdot \mathrm{s}\end{array}$ \\
\hline Distilled water & 0.893 & 1.00 & 72.8 & 0.00089 \\
Propylene carbonate & 2.12 & 1.21 & 42.6 & 0.0026 \\
Glycerol & 829 & 1.27 & 63.0 & 1.0 \\
Mixture no.1 & 1544 & 1.29 & 63.0 & 2.0 \\
Mixture no.2 & 2461 & 1.32 & 65.1 & 3.3 \\
Mixture no.3 & 6422 & 1.34 & 66.0 & 8.6 \\
Mixture no.4 & 8020 & 1.35 & 66.4 & 10.8
\end{tabular}

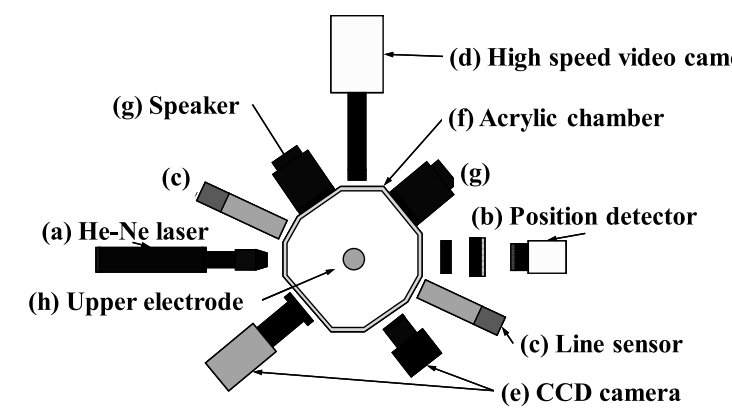

Top view of test part
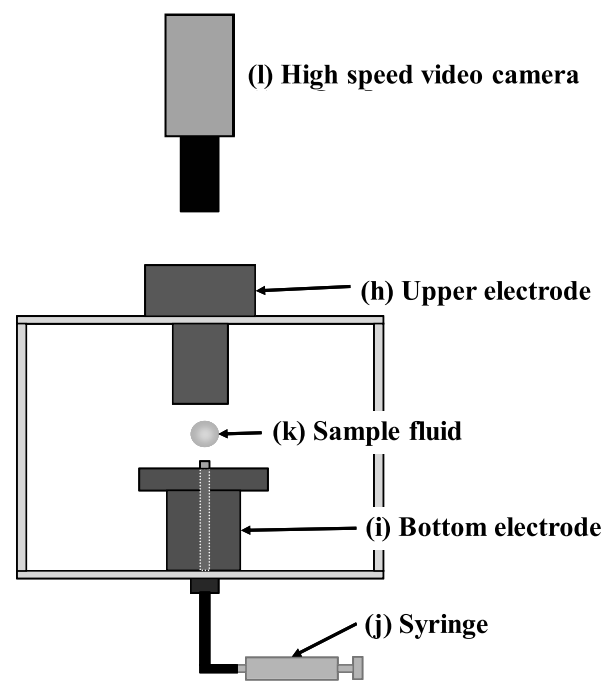

Side view of test part

Fig. 2 Schematic of experimental apparatus 


\section{3. 実験結果および考察}

\section{1 低粘性流体の回転挙動}

低粘性流体であるプロピレンカーボネートを用いて, 水平方向から回転液滴挙動を撮影した。代表的な回転液 滴の形状を Fig. 3 に示寸. 回転軸に対して軸対称形状であ る a)，b)は，それぞれ球体，回転楕円体である，一方， 伸張方向に対して軸対称形状である c), d) は楕円球, ダ ンベル形状である，e)は回転分裂した瞬間の液滴である. 浮遊液滴にかけるトルクを増加すると, 液滴は軸対称形 状から非軸対称形状に遷移し, 分裂に至る。 また低粘性 流体が回転分裂する際, 液滴は三つに分かれ, 回転中心 に微小なサテライト液滴が発生する.

次に実験結果と数值計算結果を比較するため, 観測画 像から液滴の回転数と水平方向長さを読み取る.この結 果を Fig. 4 に示寸．グラフの横軸は，無次元回転数 $\Omega / \omega_{0}$, 縦軸は, 無次元水平方向長さ $L_{\text {max }} / D_{0}$ である. ここで $\Omega$, $\omega_{0}$ はそれぞれ液滴の回転数, 共振周波数, $L_{\max }, D_{0}$ はそれ ぞれ液滴の $r$ 方向の最大長さ, 液滴の初期直径とする. 液 滴の共振周波数 $\omega_{0}$ を求めるときは, 下電極に sine 波の電 圧を印加し, 浮遊液滴に微小な振動を励起する。次にレ ーザ変位計により液滴の振動振幅の時系列データを取得 し, 高速フーリエ変換を行うことで液滴の共振周波数 $\omega_{0}$ を定める. またグラフ内の実線および点線は, Brown \& Scriven[5]の数值計算結果である. 実線は回転軸に対して 液滴が軸対称形状である場合の計算結果であり, 点線は 液滴が 2 つに分裂する場合の計算結果である.さらに $\Omega / \omega_{0}=0.26$ の点線は, 安定した液滴形状の限界を示す.こ の計算モデルでは, 非粘性非圧縮性の流体を仮定し, 一 連の回転挙動において体積は常に一定で, 表面張力によ るエネルギーと回転運動エネルギーのみが釣り合うエネ ルギーバランスから液滴の水平方向長さと回転数の関係 を算出している.

実験結果を白抜きプロットで示し, 試験流体は低粘性 流体であるプロピレンカーボネートである. 回転数の増 加に伴い, 液滴の $r$ 方向の最大幅である $L_{\text {max }}$ は増加する. しかし $\Omega / \omega_{0}=0.58$ 付近で回転数は減少に転じ, 同時に軸対 称形状から非軸対称形状に遷移する. そして $\Omega / \omega_{0}=0.26$ 付 近で回転分裂に至る，グラフより，Brown らの計算結果 と実験結果はよく一致する. a)

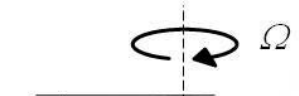

b)

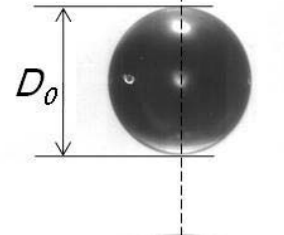

Sphere

c)

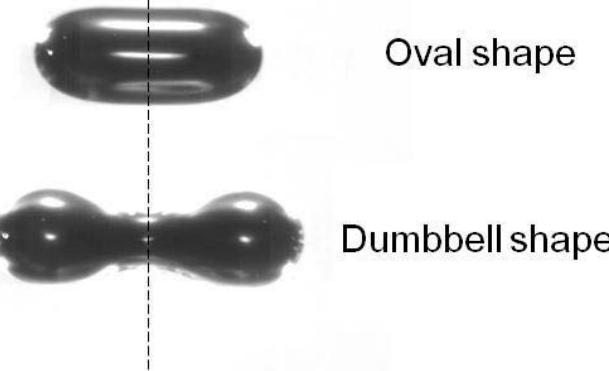

e)

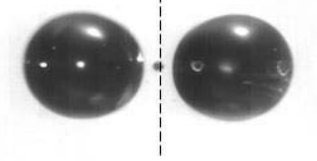

\section{Breakup}

$$
\eta=2.6 \mathrm{mPa} \cdot \mathrm{s}, D_{0}=1.65 \mathrm{~mm}
$$

Side view

Fig. 3 Rotational dynamics of low viscous fluid

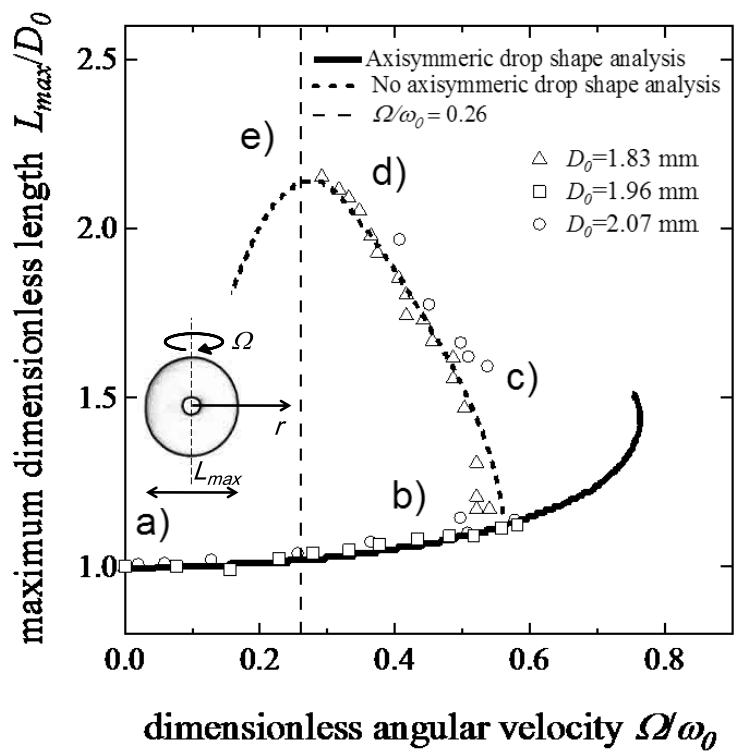

Fig. 4 Correlation between the normalized velocity and the maximum normalized length 


\section{2 高粘性流体の回転挙動}

高粘性流体であるグリセリンとグルコースの混合溶液 no. 1 を用いて, 水平方向から回転液滴挙動を撮影した. 観測画像を用いて代表的な回転液滴の形状を Fig. 5 に示 す. a')， b')， c')， d')は，それぞれ球体，回転楕円体，楕 円球，ダンベル形状であり，低粘性流体の回転挙動と同 様の傾向を示す．しかし粘性流体が分裂する直前である e’において, 低粘性流体のようにサテライト液滴は発生 せず，液滴中心部が系状(破断系)になり, 液滴は二つに分 裂することがわかる.

次に混合溶液 no. 1 より粘性の高い混合溶液 no. 4 の回転 挙動を観測し，そこで得られた液滴の回転数と水平方向 長さの関係を Fig. 6 に示す. 実験結果は, 黒塗りプロット で示し, グラフより, 軸対称形状から非軸対称形状に遷 移し, 分裂直前の $\Omega / \omega_{0}=0.26$ までは数值計算結果とよく 一致するが， $\Omega / \omega_{0}<0.26$ で $L_{\max } / D_{0}$ の数值結果と大きく 異なることがわかる。これは回転分裂直前で粘性の影響 が顕著になったと考えられる。詳細に観測すると, 回転 分裂直前の液滴形状は不安定であり, 分裂に向かって非 定常に変化する. 分裂直前で液滴の中心部直径は減少し, 水平方向の長さは増加する。 この急激な形状変化により 粘性力が抵抗力となり, 切れずに水平方向に伸び続けた と考えられる.

\section{3 回転分裂挙動を用いた粘性測定法}

回転分裂する液滴のくびれ部分に着目し, Kolte \& Szabo[6]による破断系における力のつり合いの式を本実 験体系に適用した。これを式(1)に示す。 また本実験体系 では伸長方向と重力の方向が一致しないので, 重力が分 裂に影響与えないとした。これにより粘性係数は, 表面 張力 $\sigma$ 之液滴の中心部直径 $D_{\text {mid }}$ の時間変化の比で求まる ことができる。粘性が高い流体ほど, 中心部直径の縮ま る速度が遅いという現象を表現できている。

$$
\eta_{e}=\frac{-\sigma}{d D_{\text {mid }} / d t}
$$

\section{4 回転印加が回転挙動に与える影響}

トルクのかけ方の違いで，回転分裂挙動に及ぼす影響 を調べるために，二つの異なる回転印加条件で実験を行 う。また液滴の回転は, 音響スピーカーの音圧で調整可 能である，浮遊液滴に対して，十分に分裂しうる音圧を 瞬時に印加した場合(in the case of step) と, 階段状に徐々に a')

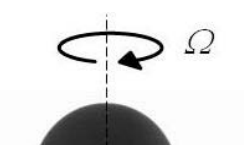

$\left.b^{\prime}\right)$

$\bullet$

Sphere

c')

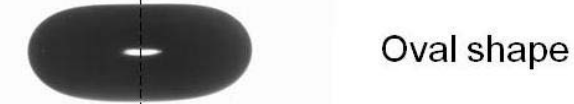

d')

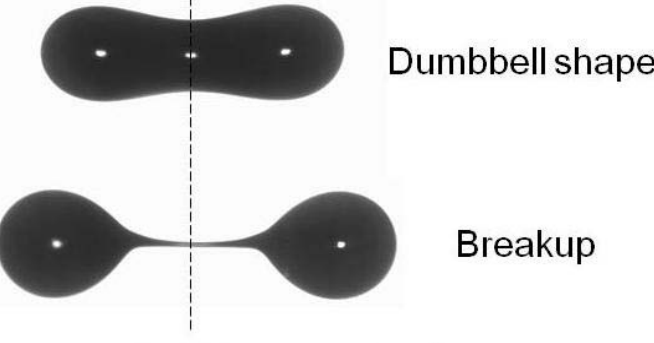

$\eta=2.0 \mathrm{~Pa} \cdot \mathrm{s}, D_{0}=1.65 \mathrm{~mm}$

Side view

Fig. 5 Rotational dynamics of viscous fluid

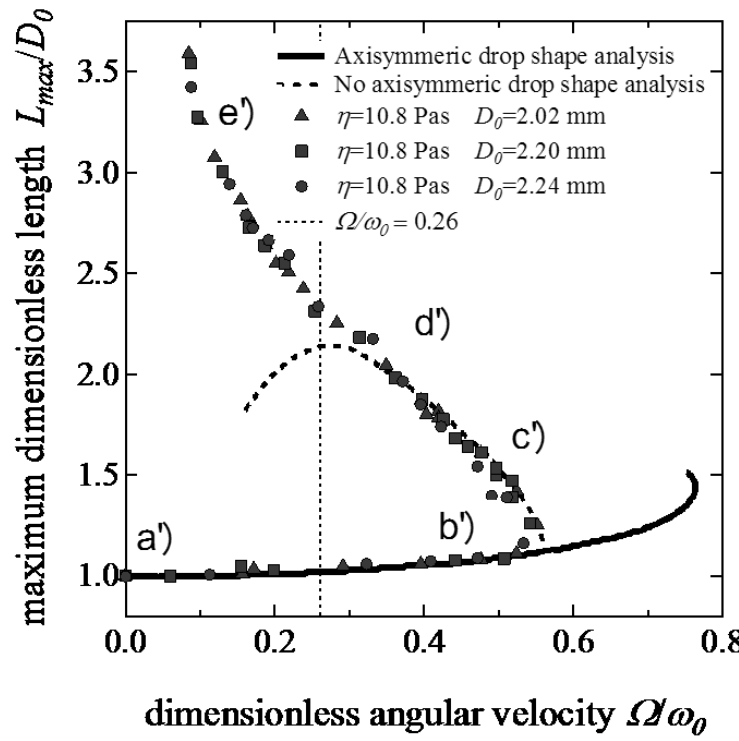

Fig. 6 Correlation between the normalized velocity and the maximum normalized length 
音圧を上昇させながら印加した場合 (in the case of stepwise)で, 液滴中心部直径の時間変化を比較する. 音圧 を瞬時に印加した場合，浮遊液滴は軸対称から非軸対称 に形状変化し，音圧を印加したところから数秒で分裂寸 る. 徐々に音圧を印加した場合, 浮遊液滴はダンベル形 状で準安定状態となり，次の瞬間に回転分裂する.

高粘性流体として $\eta=2.0 \mathrm{~Pa} \cdot \mathrm{s}$ の混合溶液 no. 1 を用いた 瞬時に音圧を印加した場合の実験結果を Fig. 7(a)と(b)に， 徐々に音圧を印加した場合の実験結果を Fig. 8(a) と(b)に 示寸. 縦軸は液滴の中心部直径 $D_{\text {mid }}$, 横軸は回転分裂時 を $0.0 \mathrm{sec}$ とした時間軸とする.ただし液滴が回転軸に対 して軸対称である場合は中心部直径を水平方向長さとし ている.グラフ内には液滴初期直径 $D_{0}$ が 1.9 から $2.8 \mathrm{~mm}$ の結果を示す. Fig. 7(a)によると, $-1.0 \mathrm{sec}$ 付近を越えて, 中心部直径が急激に減少している。これは液滴が軸対称 形状から非軸対称形状に遷移した瞬間である。

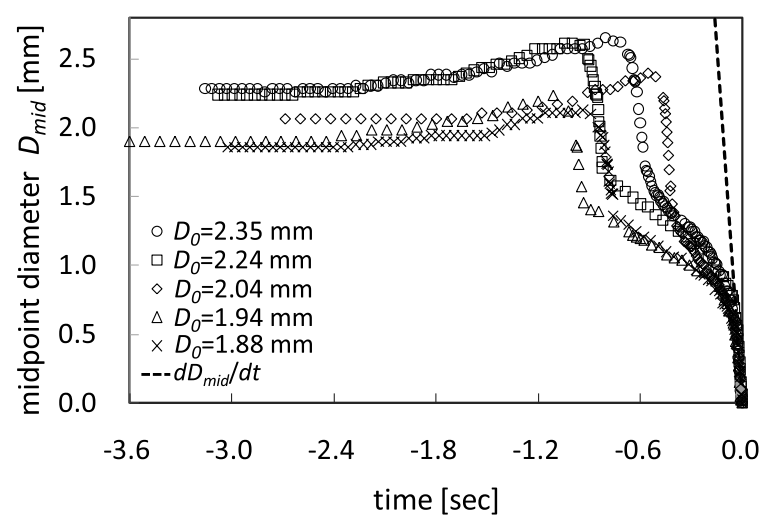

(a) Midpoint diameter

Initial
condition
$D_{0}=2.35 \mathrm{~mm}$
$\eta=2.0 \mathrm{~Pa} \cdot \mathrm{s}$
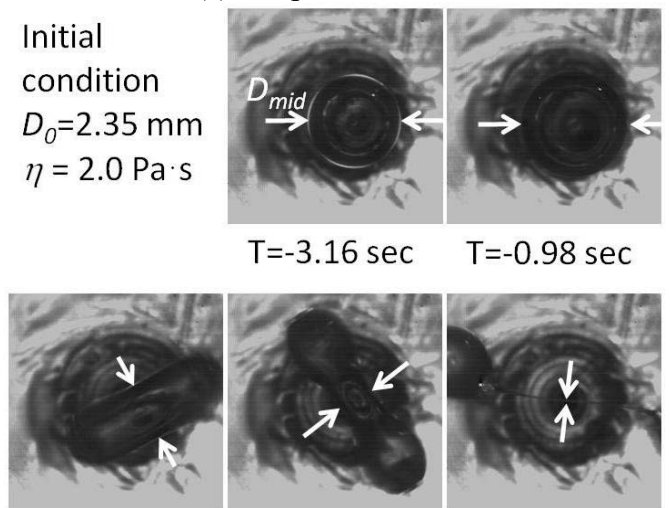

$\mathrm{T}=-0.45 \mathrm{sec} \quad \mathrm{T}=-0.09 \mathrm{sec} \quad \mathrm{T}=0.0 \mathrm{sec}$

(b) Top view of levitated drop

Fig. 7 Rotational dynamics of high viscous fluid in the case of step input

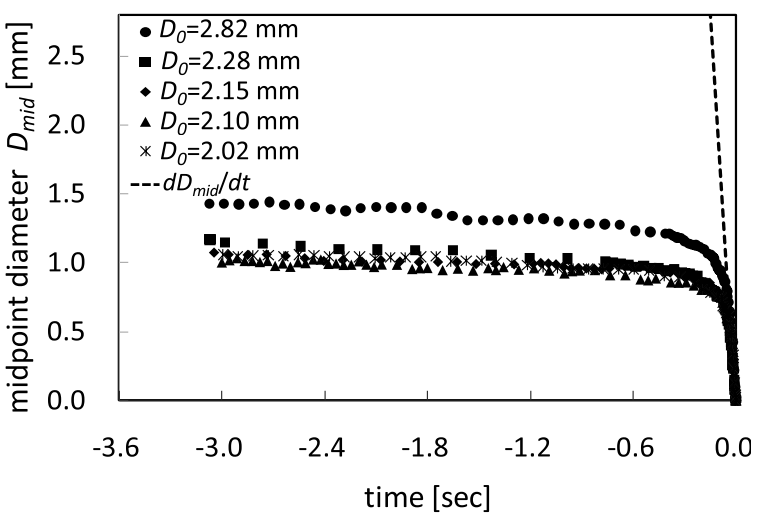

(a) Midpoint diameter
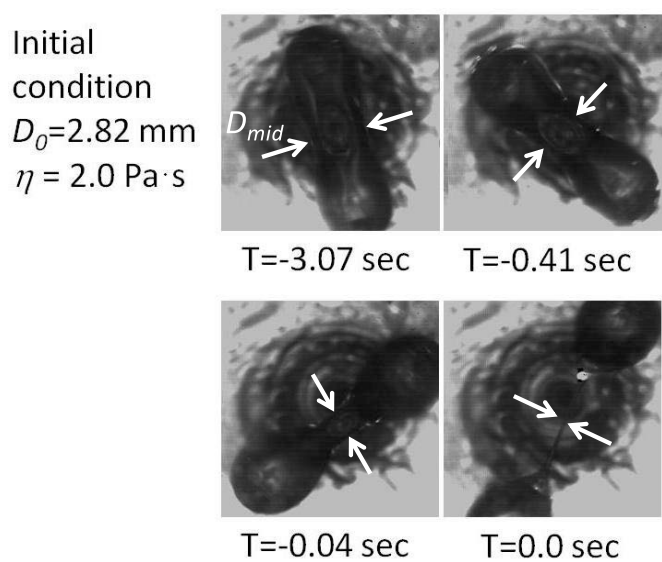

(b) Top view of levitated drop

Fig. 8 Rotational dynamics of high viscous fluid in the case of stepwise input

Fig. 8(b)によると, Fig. 8(a)内の全てのプロットは非軸対称 形状である．また約-3.0 sec から-0.6 sec の間が，液滴が次 の瞬間分裂に至る準安定状態である. Fig. 7, 8 によると， 液滴初期直径によらず，分裂に向かうほど中心部直径は 収束することがわかる，すなわち回転の印加方法の違い は，液滴の体積によらず，物性に依存し，粘性を決定で きることが示唆される.

\section{5 回転分裂挙動を用いた粘性測定結果}

回転分裂直前の中心部直径の時間変化を粘性算出式(1) に代入し，粘性算出結果を Fig. 9 に示す．グラフの横軸 はウベローデ粘度計で計測した值を示し，縦軸は式(1)よ り算出した粘性係数を示す，グラフ内の白抜きのプロッ ト，黒塗りのプロットは，それぞれ瞬時に音圧を印加し た場合の実験結果，徐々に音圧を印加した場合の実験結 果である. 同一の試料流体で複数回実験し，粘性算出値 
の平均值をプロットで示し, エラーバーを標準偏差で表 している. 同じグラフより，実測值よりも粘性算出值の 方が高い值を示すが, 実測值と粘性算出值は比較的一致 することがわかる．回転液滴が分裂する直前には，急激 な形状変化に伴うため, 粘性力だけでなく表面張力など が液滴の形状変化を妨げる方向に力が働き, 液滴のくび れ部が縮みづらくなる. 式(1)は近似式であり, 曲率を 1 と仮定していることから, 回転分裂直前の中心部直径の 時間変化が低い值となり, 粘性算出值が実測值よりも大 きく見積もられた可能性があると考えられる.より精度 を上げるためには，時々刻々変化する曲率の評価を含め, 実際に液滴の破断部に作用する力として表面張力などを 考慮する必要があると考えられる.

\section{4. 結 論}

静電浮遊液滴の回転分裂挙動から粘性測定を行った結 果, 以下の結論が得られた．粘性の影響が顕著になる回 転分裂挙動を観測することで, 粘性係数を算出した. こ れらにより以下の知見が得られた。

1. 粘性液滴の回転分裂挙動において, 液滴の中心部の時 間変化を利用することで，粘性係数を見積もることが できた。

2. 徐々に音圧を印加する場合と瞬時に音圧を印加する場 合で粘性を算出した結果, 粘性係数 $\eta=2.0 \mathrm{~Pa} \cdot \mathrm{s}$ の高粘 性流体においては大きな違いは見られなかった。

3. 粘性範囲 $1 \mathrm{~Pa} \cdot \mathrm{s}<\eta<10 \mathrm{~Pa} \cdot \mathrm{s}$ において, 液滴の回転挙 動を利用することで非接触粘性測定の可能性が示唆さ れた.

\section{[謝辞]}

本研究は, 宇宙航空研究開発機構 宇宙環境利用科学委 員会研究班ワーキンググループ「浮遊液滴非線形ダイナ ミクス」の活動の一環として実施したものである. 本研 究を実施するにあたり, 東京大学の西成活裕教授, 日本 原子力研究開発機構の渡辺正研究主幹には貴重なご助言 を頂いた. ここに記して感謝の意を表する.

\section{NOMENCLATURE}

\footnotetext{
$\eta \quad$ : Viscosity, Pa.s

$v \quad:$ Kinematic viscosity, $\mathrm{mm}^{2} / \mathrm{s}$

$\sigma$ : Surface tension, $\mathrm{mN} / \mathrm{m}$
}

$\Omega \quad$ : Rotational velocity, $\mathrm{Hz}$

$\omega_{0}$ : Resonance frequency, $\mathrm{Hz}$

$D_{0} \quad$ : Initial diameter, $\mathrm{mm}$

$D_{\text {mid }}$ : Midpoint diameter, mm

$L_{\max }$ : Maximum length, mm

$\eta_{0} \quad$ : Measured viscosity, $\mathrm{Pa} \cdot \mathrm{s}$

$\eta_{e} \quad$ : Estimated viscosity, $\mathrm{Pa} \cdot \mathrm{s}$

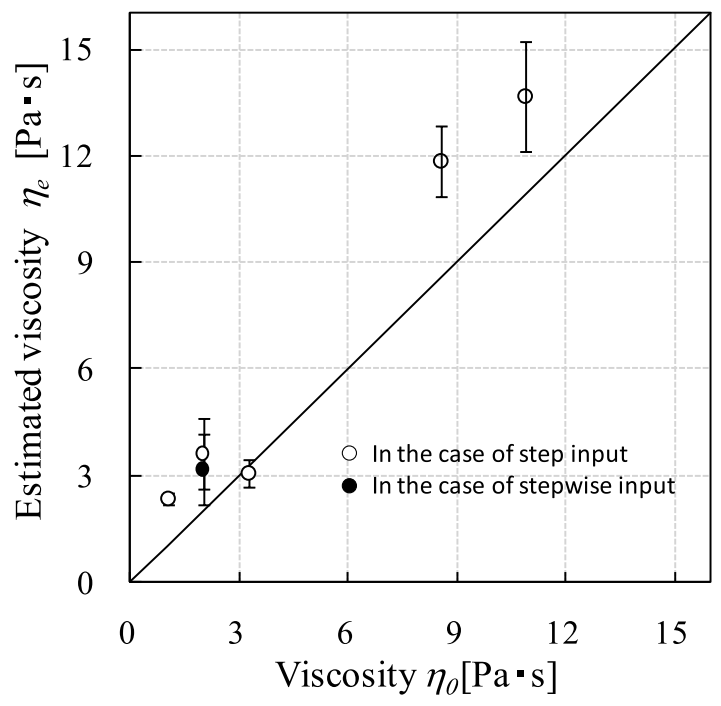

Fig. 9 Estimated viscosity

\section{参考文献}

[1] W. K. Rhim, K. Ohsaka, P. F. Paradis, and R. E. Spjut ; "Noncontact technique for measuring surface tension and viscosity of molten materials using high temperature electrostatic levitation", Rev. Sci. Instrum., 70 (1999) 2796-2801.

[2] T. Ishikawa, P. F. Paradis, and S. Yoda ; "Noncontact surface tension and viscosity measurements of rhenium in the liquid and undercooled states", Appl. Phys. Lett., 85 (2004) 5866-5868.

[3] K. Ohsaka, A. Rednikov, S. Sadhal and E. H. Trinh ; "Noncontact technique for determining viscosity from the shape relaxation of ultrasonically levitated and initially elongated drops", AIP Conf. Proc., 73 (2002) 2091-2099.

[4] W. K. Rhim, S. K. Chung, and D. D. Elleman ; "Experiments on rotating charged liquid drops", AIP Conf. Proc., 197 (1990) 91-105.

[5] R. A. Brown, and L. E. Scriven ; "The Shape and Stability of Rotating Liquid Drops", Proc. R. Soc. Lond., 371 (1980) 331-357.

[6] M. I. Kolte, and P. Szabo ; "Capillary Thinning of Polymeric Filaments", J. Rheology., 43 (1999) 609-626.

[Received Mar. 29, 2011, Accepted Nov. 30, 2011] 